\title{
A PRODUÇÃO DOS ESPAÇOS PÚBLICOS A PARTIR DA PERSPECTIVA DOS LARGOS DA CIDADE DE PORTO ALEGRE
}

\author{
The producrion of the public spaces partners from the squares perspective of the city of \\ Porto Alegre
}

Rosiéle Melgarejo da Silva*

*Doutora em Geografia pelo PPG UFRGS - rodageo@yahoo.com.br.

Recebido em 15/05/2018. Aceito para publicação em 25/06/2018.

Versão online publicada em 10/08/2018 (http://seer.ufrgs.br/paraonde)

\begin{abstract}
Resumo: Com este trabalho pretende-se refletir a produção do espaço dos largos, frente ao universo dos espaços públicos contemporâneos. A tese é a de que os espaços públicos dos largos se constituíram como redutos de apropriações alternativas. Assim, divergente da lógica das "revitalizações urbanas", pautadas na especulação imobiliária, os largos resistiram e consolidaram uma produção do espaço de caráter popular. Além disso, o desenvolvimento do trabalho apresenta uma proposta metodológica que perpassa os conceitos norteadores da Geografia a fim de ampliar e tornar múltipla a apropriação teórica. Assim, através do conceito de paisagem, espaço, território e lugar, os largos trazem a tona uma realidade clandestina e subterrânea da vida social dos espaços públicos.
\end{abstract}

Palavras-chave: Geografia; Análise Territorial; Análise Espacial.

\begin{abstract}
With this work we intend to reflect the production of the space of the square, in front of the universe of contemporary public spaces. The thesis is that the public spaces of the square were constituted as redoubts of alternative appropriations. Thus, divergent from the logic of "urban revitalizations", based on real estate speculation, the squares resisted and consolidated a production of the space of popular character. In addition, the development of the work presents a methodological proposal that crosses the guiding concepts of Geography in order to broaden and make multiple the theoretical appropriation. Thus, through the concept of landscape, space, territory and place, the squares bring to light a clandestine and subterranean reality of the social life in the public spaces.
\end{abstract}

Key-words: Geography; Territorial Analysis; Spatial Analysis.

\section{Introdução}

O presente trabalho visa ampliar a noção de espaço público através da perspectiva do espaço dos largos. Os largos que serão apresentados como protagonistas desse movimento de expansão do conceito de espaço público se localizam na cidade de Porto Alegre, e se colocam como estudo de caso singular, porém não inédito no contexto urbano brasileiro.

Quando tratamos de refletir sobre o espaço público, de imediato nos é remetido a um conjunto de entidades morais, esferas da ação social e relações de poder dotadas de positividade, interrompidas por índices de violência. Essa noção totalizante do espaço público acaba por englobar uma diversidade de formas espaço-temporais dos mais variados, que se contrapõe a riqueza das diferentes perspectivas que esses lugares podem propiciar.

Os largos, de modo geral, são lugares que se diferem no que tange a estrutura física e às relações de poder que se identifica como características singulares, frente ao universo dos espaços públicos. Eles contam com um número pequeno de equipamentos urbanos, como bancos, área verde com sombra, ou todos aqueles que fazem relação com um lugar de parada e não só de passagem. Quanto a teia social 
que se desenvolve nos largos, os grupos mais presentes são de artistas de rua, comércio informal, moradores de rua, pontos de referência de atividades políticas, e algumas atividades ilegais, como tráfico de drogas, prostituição e pequenos roubos a pedestres. Logo, os largos da cidade tendem a atrair uma cena alternativa e clandestina no centro da cidade.

Dessa forma, o questionamento que moveu esse trabalho é a de se os largos da cidade de Porto Alegre seriam meras superfícies escolhidas aleatoriamente por parte dessas apropriações alternativas, ou se realmente ali foi gestado um potencial espacial para a reprodução e manutenção dessas relações de poder específicas.

A fim de elencar elementos para uma reflexão mais aprofundada do assunto, iremos usar uma metodologia através de conceitos norteadores da Geografia e com isso provocar os limites da multiplicidade dessa perspectiva. Apresentar o múltiplo é complexo e como metodologia optamos por um caminho onde a trilha se faz através dos conceitos da Geografia. Um caminho repleto de portas e obstáculos, abertos um a um a partir da realidade sensível dos largos, e assim de sua paisagem, em seguida através de espaço, e com a noção da amplitude dessa multiplicidade adentrar nas geometrias de poder através de seus territórios e por fim voltar ao lugar, onde o local e o global se cruzam e dão cores para o que antes não era diferenciado.

Assim, os conceitos serão as ferramentas para evidenciar um espaço integrado ao nosso dia a dia e que passa despercebida em nossas passagens cotidianas. Diferentes conceitos que não tendem a se perder do foco da pesquisa, pois irão orbitar em torno do objetivo deste trabalho que é analisar a dimensão dos largos na produção dos espaços públicos da cidade de Porto Alegre. Mas para isso, primeiramente é importante elencar os dados históricos que sustentam o questionamento e evidenciam dados para encaminhar possíveis respostas.

O desenvolvimento deste trabalho é resultado de uma pesquisa feita durante quatro anos que contou com observações, entrevistas e que se constituíram como o material empírico que embasou as considerações que estão expostas a seguir.

\section{Desenvolvimento}

\subsection{A trajetória dos Largos}

Os espaços públicos no Brasil possuem sua origem em espaços acidentais, como em vazios ou alargamentos da estrutura urbana, entorno de igrejas, entorno de mercados e que, com o tempo foram apropriados e usados para convivência da comunidade. Estes teriam sua inserção definitiva na estrutura urbana a partir do Renascimento, passando a fazer parte obrigatória destas cidades a partir dos séculos XVIII e XIX.

Por volta de 1920 a cidade de Porto Alegre passou por vários projetos de remodelação urbana, que contavam com intervenções que prometiam embelezamento e modernização da cidade para uma elite. Foi nesse momento que vários largos se tornaram praças e parques, pois os largos tinham como referência o que nesse momento era divulgado como "vida mundana". Assim, esses espaços eram por referências locais da mendicância, prostituição, jogo, atividades ilegais em geral e de vivência dos mais pobres. Mas antes de tratar dessas transformações e das reais intenções que estavam por trás dos discursos de melhoramento da cidade, vejamos como se localizavam os principais largos em Porto Alegre no século XIX. As referências dessas informações foram retiradas de dois trabalhos do historiador Charles Monteiro (1995; 2006), onde é abordada a memória e cultura urbana da cidade de Porto Alegre através desse momento de remodelação urbana e usa como fonte cronistas que narraram às múltiplas vivências na cidade. 


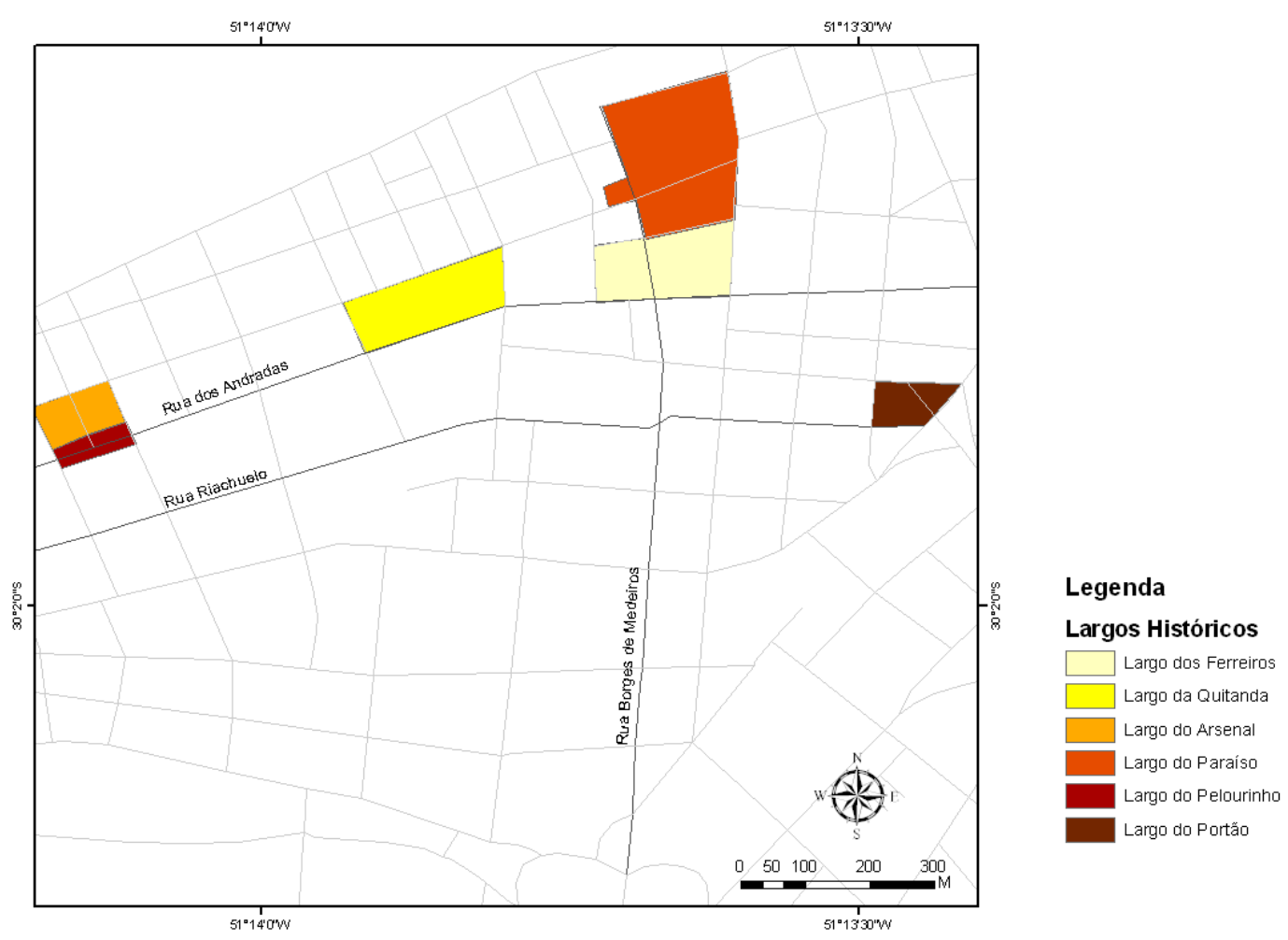

Mapa 1: Mapa de localização dos largos do século XIX

Fonte: Base Cartográfica do IBGE.

Esses largos caracterizados no mapa anterior possuem seus primeiros registros históricos no século XVIII, alguns sofrem os efeitos dos projetos de remodelação do início do século XIX e outros permanecem pelo século XX e XXI com nomenclaturas, limites e usos diferentes, porém ainda existentes nessas ou próximas dessas localidades. Para compreender o que os largos significavam na vida urbana dessa trajetória histórica, segue uma definição de seus locais, tanto antes como onde estariam na configuração atual, e as atividades desenvolvidas nesses espaços, que já oferecem pistas do tipo de apropriação nesses espaços.

O Largo da Quitanda se localiza onde hoje é a Praça da Alfândega. E quanto às atividades, praticava-se o comércio, principalmente de amendoim, lenha, hortifruti-granjeiros, carnes e ovos. Foi onde surgiu o primeiro trapiche, na margem do Guaíba ainda, em 1804. Local de reunião de comerciantes e quitandeiras (maior parte negros) com seus tabuleiros. Com a construção da Alfândega, as quitandeiras são removidas para o Largo do Paraíso. Porém acontece a resistência das quitandeiras, e elas são autorizadas pela Câmara a ocupar o ângulo oeste do Largo da Quitanda, assim como os Largos do Paraíso e do Pelourinho. Esse é o primeiro logradouro a ter serviço de asseio público, com a remoção dos detritos que eram jogados.

O Largo dos Ferreiros se encontrava entre o Beco da Ópera (atual Rua Uruguai) e a Rua Bragança (atual Rua Marechal Floriano). Um terreno plano e aberto à beira do Guaíba e seguia o alinhamento do Caminho Novo (atual Rua Voluntários da Pátria). Nesse local ocorriam oficinas para atender o comércio que atracava no trapiche do Largo da Quitanda. Posteriormente foi chamado de Largo do Paraíso.

O Largo do Paraíso contemplava o que hoje é a atual Praça XV de Novembro, Chalé da Praça XV e boa parte do que hoje é a Praça Montevidéu e Mercado Público. Inicialmente foi dominada por tabernas e casas de prostituição. E após a construção da Alfândega, as quitandeiras são transferidas para o Largo do Paraíso. Até 1842 o comércio era feito desordenadamente pelo Largo da Alfândega e Largo do Paraíso, até que Saturnino de Souza (Governador da Província) constrói um mercado onde atualmente se encontra o Chalé da Praça XV. Era um prédio simples de tijolos e portões de ferro, onde 
se comercializava carnes, aves, frutas e hortigranjeiros (com regulamento amplamente discutido na Câmara). Em 1870 o Largo passa por transformações, pois ele precisava ser ampliado para atender as exigências da cidade. Em 1875 o Conselho Municipal opta pela construção de um novo mercado, no alinhamento do Caminho Novo (primeiro andar do atual Mercado Público). A partir de 1900 realizamse obras para escoamento das águas pluviais e pavimentação, transformando esse espaço em Praças XV de Novembro e Praça Montevidéu.

O Largo do Pelourinho se encontrava em frente à Igreja das Dores (1807). Também chamado de Largo da Forca por alguns historiadores. Onde foi construído o pelourinho em que os homens escravizados eram açoitados. Lugar de "ritualização" da ordem na sociedade colonial e seu uso conservado e regulamentado pelo Conselho Municipal de Porto Alegre. Serviu para o comércio miúdo depois da saída das quitandeiras do Largo da Quitanda. E era lugar preferido para as festas religiosas.

O Largo do Arsenal foi o espaço fronteiriço entre a Igreja das Dores e o Largo do Pelourinho. O Largo do Arsenal e o Largo do Pelourinho, pela proximidade, em algum momento podem ter sido um largo só. Também chamado de Largo da Forca, Praia do Arsenal e Praça Harmonia. Existe uma controvérsia quanto às atividades desenvolvidas ali. Pois alguns pesquisadores acreditam que ali estava instalada a forca, para outros ela estaria no Largo da Forca, no espaço em frente à Igreja das Dores. Aqui estaria localizado o primeiro cemitério de povoação (deslocado depois para os altos da colina - por onde hoje se encontra o Teatro São Pedro -com a construção da Igreja da Matriz). Onde se localizava a cadeia e o arsenal de guerra. Pela sua importância, serviu de referência com esse nome por boa parte do século XIX.

O Largo do Arsenal era habitado por casebres e estaleiros da população pobre. Ocasionalmente serviu para a execução dos condenados à forca (repetida até 1860, onde toda a população comparecia). Em 1860 se torna Praça da Harmonia "com o plantio de árvores e a colocação de bancos de madeira para o recreio da população" (MONTEIRO, 1995, p. 31) E assim, houve ajardinamento e foi murada para uso da elite local. A partir de 1900 passa por reformas e se torna o "mais lindo passeio da cidade às margens do Guaíba" (MONTEIRO, 1995, p. 35). Na virada do século também foi instalada um ringue de patinação. Dessa forma, o mais provável é que de largo da Forca se tornou Largo do Arsenal e por fim se transformou em Praça Harmonia, que por fim foi destruída em função da necessidade da expansão da área portuária e por sua ligação com o ramal ferroviário.

0 Largo do Portão ficava em frente ao portão da vila para onde convergiam as três ruas principais: Rua da Igreja (Rua Duque de Caxias), Rua da Ponte (Rua Riachuelo) e a Rua da Praia (Rua Andradas). Ele permaneceu na memória coletiva por muito tempo, pois o nome do largo traz como referência onde já teria sido os limites da cidade. Rodeado por uma série de moradias, tabernas, farmácia, armazém de secos e molhados e duas vendas era ponto de referência da redondeza.

Como podem ser observados, os largos se constituíam como espaços centrais da vida urbana, assim como uma evidente importância para a memória e identidade da cidade de Porto Alegre. Em função das transformações, que podemos comparar suas práticas até com as atuais políticas de revitalização, esses largos se tornaram parques e praças. Essa transformação além de intervir na estrutura e modelagem do espaço, expulsava o comércio e festas populares que ocorriam nesses lugares.

A alteração nos largos acabava transformando todo o perfil do entorno, pois junto com ela ocorriam derrubadas de árvores, aberturas de avenidas no lugar de ruelas e becos para que uma nova classe social se apropriasse do local. Apresenta Charles Monteiro (2006), em seu resgate histórico através de cronistas que contaram o cotidiano de Porto Alegre no início do século XX, que nem todos estavam satisfeitos com as mudanças, como assim diz Aquiles, um dos cronistas usados como fonte:

Aquiles observava que a transformação dos espaços e equipamentos urbanos, o embelezamento da cidade e a nova velocidade dos deslocamentos e comunicações, produziu uma nova cultura e experiência de vida urbana. Porém, na contramão provocaram a sensação de perda e descontinuidade em relação às antigas referências socioespaciais, o que foi percebido pelo autor como empobrecimento da experiência urbana (MONTEIRO, 2006, p. 307).

ParaOnde!?, Porto Alegre, v.9, n.2, p.138-148, 2018. Edição Especial: XII ENANPEGE http://seer.ufrgs.br/paraonde 
A perda desses espaços de sociabilidades populares significava o começo de uma nova cultura urbana na cidade. 0 espaço urbano deveria estar em consonância ao crescimento industrial e o espaço público deveria atender a uma classe em ascendência. Essa nova classe burguesa não se restringia aos espaços privados dos "saraus" que ocorriam dentro de suas casas, ou aos clubes, e assim ela forjou espaços públicos que na verdade atendiam a interesses privados. Porém, muitos largos se mantiveram na cidade e essa história carregada de significado não foi consumido totalmente pela privatização dos espaços públicos. A seguir, o mapa ilustra os largos ainda presentes atualmente na cidade de Porto Alegre.

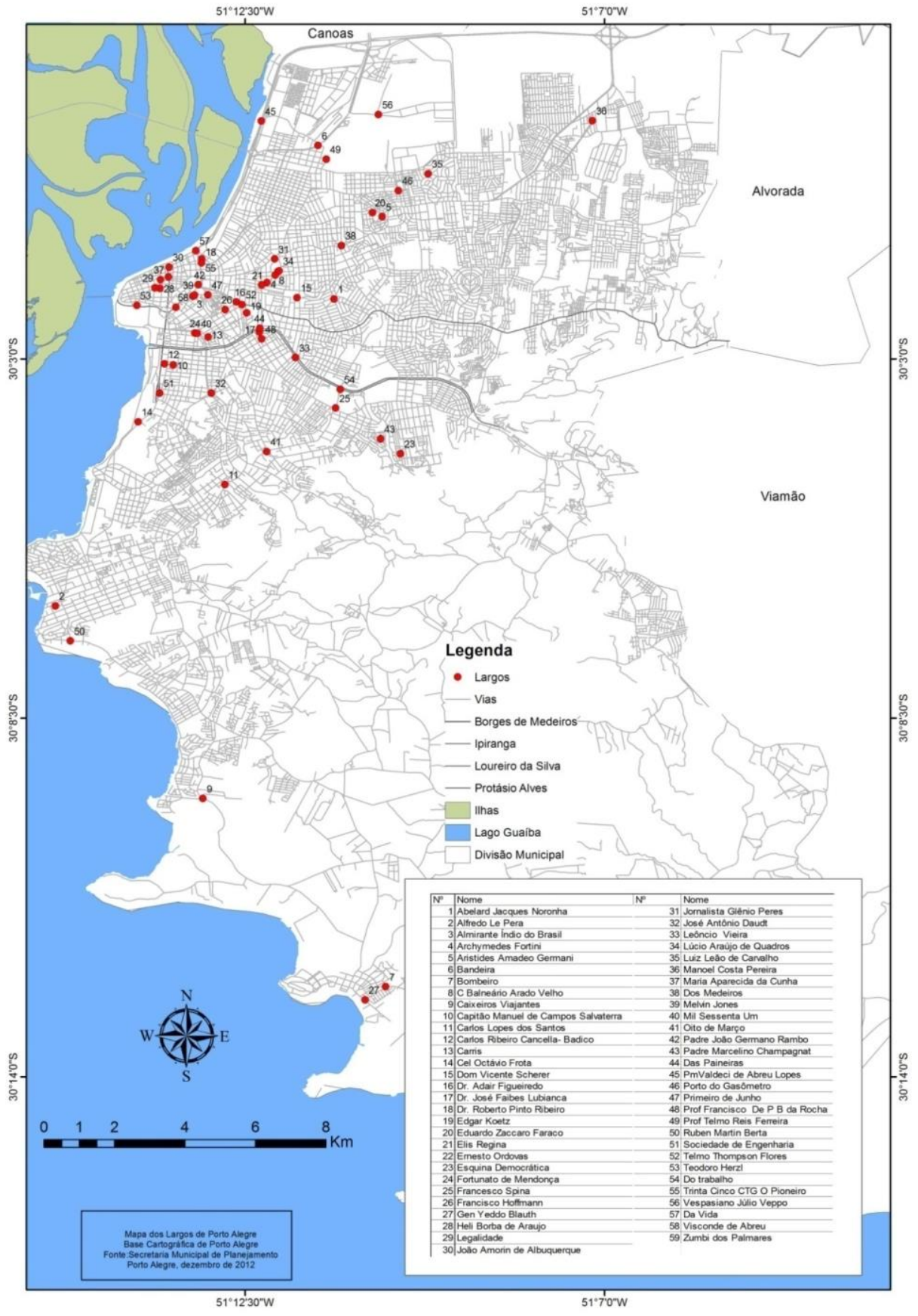

Mapa dos Largos de Porto Alegre

Fonte: Secretaria Municipal de Planejamento de Porto Alegre, 2012. 
E assim, nos dias de hoje ainda podemos chegar em Porto Alegre, passar pelo Largo Glênio Peres, Largo Zumbi dos Palmares e Largo Esquina Democrática, por exemplo e sentir como essa histórica apropriação popular se manteve através de um pequeno comércio, dos artistas de rua e das organizações políticas que se usam desses lugares como referência de algo que foi apropriado.

\subsection{Dos caminhos e possibilidades: a paisagem, o espaço, o território e o lugar}

0 presente trabalho pretende, mesmo que rapidamente, propor uma reflexão sobre a dimensão dos largos na produção dos espaços públicos da cidade de Porto Alegre. Como dimensão entende-se tratar de uma leitura dialética do espaço, que é composta por uma dimensão física e outra subjetiva ou das ações e práticas socioespaciais. Dessa forma, pretendemos analisar as relações de poder que as estruturas materiais urbanas, a lógica de mercado e as diferentes apropriações sociais, desde movimentos sociais organizados como de indivíduos independentes, exercem sobre a produção desses espaços públicos. E ainda sobre a produção do espaço, comenta Henri Lefebvre:

Então, de que se trata? De uma produção, a de um espaço. Não somente de um espaço conceitual e ideal, de um lugar dos espíritos, mas de um espaço social e mental. De uma emergência. Da decodificação do espaço anterior. 0 pensamento e a filosofia emergem, subindo das profundezas, mas é também a vida que se decodifica, a sociedade inteira, com o espaço (LEFEBVRE, 1974, p. 301).

A investigação apontou destaque para três largos em específico, que desenvolveram alto nível de apropriação por parte das coletividades e movimentos sociais, que são: Largo Esquina Democrática (localizado no centro da cidade), Largo Glênio Peres (localizado em frente ao Mercado Público da cidade) e Largo Zumbi dos Palmares (localizado no bairro Cidade Baixa). E foi através desses largos em especial que a metodologia de trabalho foi desenvolvida e colocada em teste. A seguir, três fotografias, cada uma representando um pouco do cotidiano desses largos citados anteriormente:

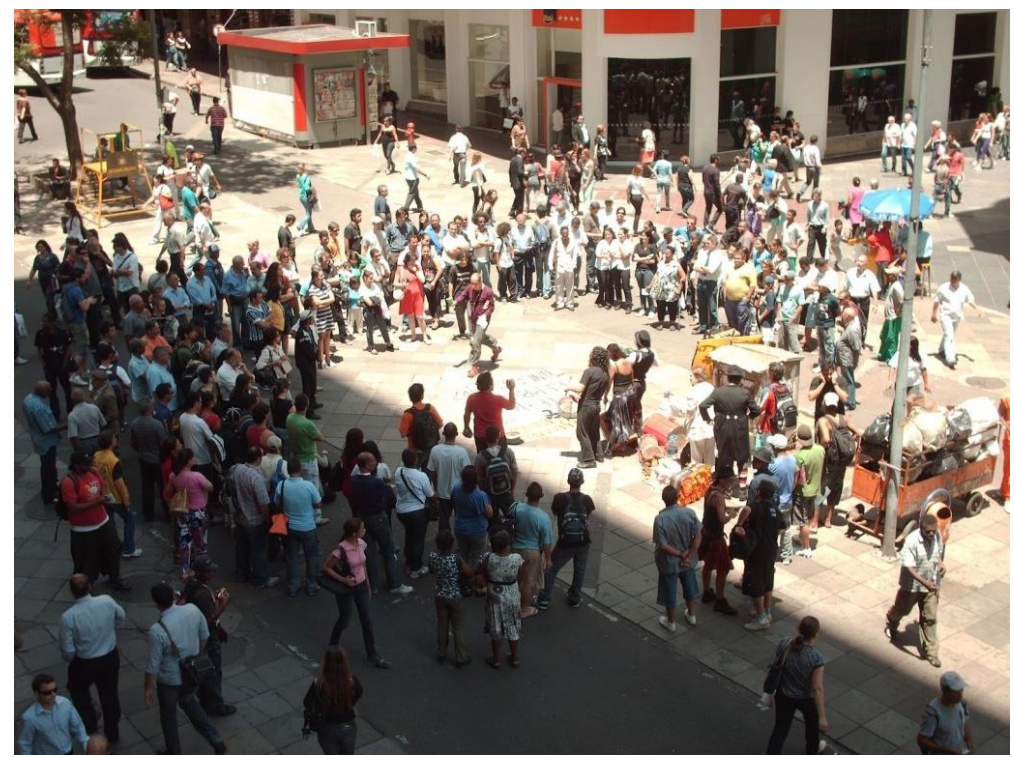

Largo Esquina Democrática

Fonte: Teatro Levanta Favela, 2011. 


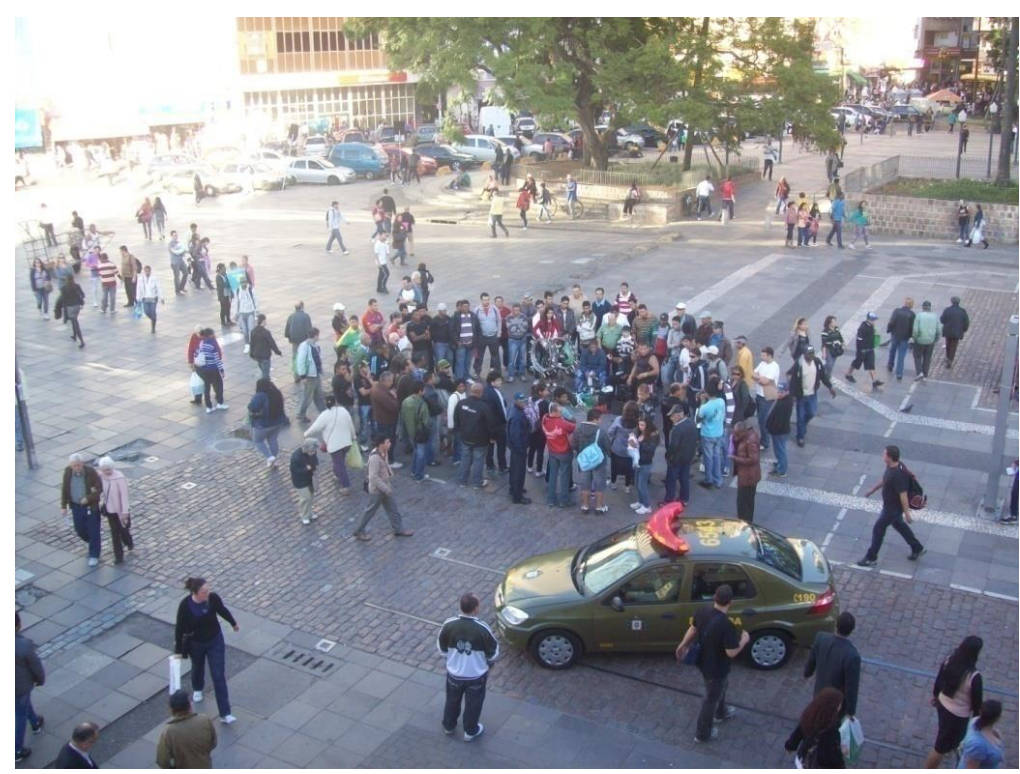

Largo Glênio Peres

Fonte: acervo da autora, 2013.

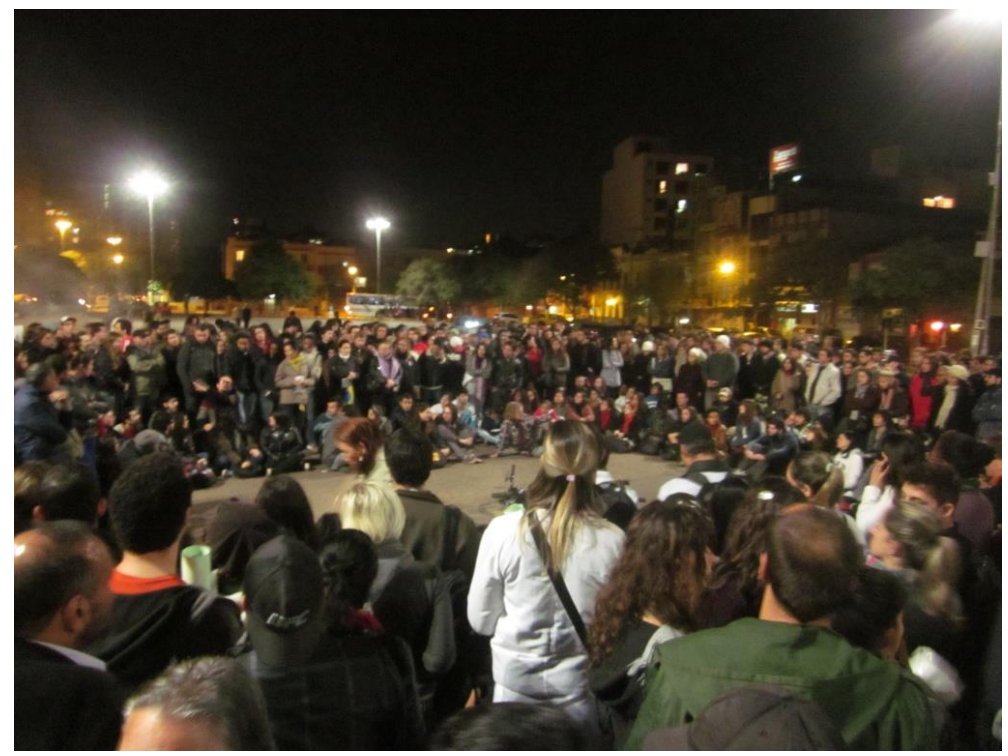

Largo Zumbi dos Palmares

Fonte: Jornalismo B, 2013.

Abrir as portas da paisagem dos largos é desconfiar e duvidar do que de imediato se torna aparente. A primeira impressão dos largos se resume a momentos de passagem, do típico vai e vem cotidiano. A velocidade imposta na contemporaneidade exige uma parada e um olhar mais detido sobre o que está fixo no largo e ao que se movimenta em direção ao próprio, e ao que enfim se liga a esse espaço com práticas e identidades. Assim, a paisagem compõe uma cena, como nos diz Paulo César da Costa Gomes:

De fato essa cena é uma espécie de discurso que se constrói por meio de certos gestos, pela maneira de se apresentar (em grupo, sozinho, com família, etc.), pelas atividades desenvolvidas; pelas imagens criadas e lidas a partir de certos elementos, com roupas e acessórios; e pelos comportamentos, a maneira de falar e se conduzir em face da diversidade de circunstâncias oferecidas nesse espaço. Os itinerários, os percursos e as paradas são igualmente significativos, demonstrando uma escola, uma forma de particularizar e valorizar diferencialmente esse espaço (GOMES, 2010, p. 164 e 165). 
A quebra das condições temporais velozes que pressionam o cotidiano contemporâneo das grandes cidades desvenda uma paisagem nos largos, e revela um padrão nas atividades que tendem a se fixar nesses lugares. Os largos se conectam em função dessa continuidade, despercebida e engolida por uma lógica mercadológica da cidade, onde a produção máxima dos lucros impede a expansão do tempo lento das atividades artísticas, políticas e dos pequenos comércios de rua.

Os largos da cidade de Porto Alegre, a exemplo de todo o contexto urbano da cidade possui impressa as marcas dos privilégios e das exclusões. 0 aumento do controle, através da vigilância de câmeras e da presença mais ostensiva do aparato policial em praças e parques faz dos largos os redutos das práticas, que cada vez menos tem sido bem-vinda nos espaços públicos.

No caso desta cidade, especificamente, as estratégias de controle contam com um aparato de leis que atingem os largos mais centrais da cidade, e por isso com maior atração, restringindo e dificultando a ocorrência de atividades espontâneas. A exemplo disso, a Lei 07.203 que disciplina a realização de eventos culturais, econômicos, políticos e de outra natureza no Largo Glênio Peres, demonstra o interesse do poder público de não permitir que largos possam se autogerir em função de suas particularidades. O largo, dessa forma, revela sua dimensão conflituosa, um verdadeiro campo de batalha, como na definição a seguir:

Espaço público tornou-se um dos campos de batalha centrais dentro do urbano contemporâneo. Reconhecido pela maioria dos teóricos urbanos como uma dimensão essencial da vida urbana, não existe uma definição simples de apenas o que o espaço público é, ou certamente deve ser. No seu mais básico, o espaço público é simplesmente o espaço utilizado em comum por parte do público (LATHAM, 2009, p. 177).

Na trilha, do caminho metodológico proposto, o espaço apresenta outra dimensão do objeto e amplia nossa percepção sobre o assunto. Tanto como resultado, produzido, ou como agente, produtor de um espaço caracterizado por relações irregulares, múltiplas e dinâmicas. A partir da noção de espaço, percebemos a importância de um entendimento desses lugares de uma maneira globalizante e não totalizante recheado de relações conflitantes ou solidárias, conforme a perspectiva de análise. A dimensão espacial revela assim, a riqueza da multiplicidade e a amplitude das conexões, impulsionada pelo patrimônio material e imaterial dos espaços verdadeiramente relacionais:

Se o tempo se revela como mudança, então o espaço se revela como interação. Neste sentido, o espaço é a dimensão social não no sentido da sociabilidade exclusivamente humana, mas no sentido do envolvimento dentro de uma multiplicidade. Trata-se da esfera da produção contínua e da reconfiguração da heterogeneidade, sob todas as suas formas - diversidade, subordinação, interesses conflitantes. À medida que o debate se desenvolve, o que começa a ser focalizado é o que isso deve trazer à tona: uma política relacional para um espaço relacional (MASSEY, 2008, p. 97 e 98).

O espaço, enquanto produção e produtor, tende a revelar um produto espacial dos largos diferenciado e vital para esses grupos que nele e dele se ligam. Desde o contexto histórico dos largos, até os usos e apropriações na contemporaneidade revelam que as relações efêmeras e de passagem no cotidiano também possuem continuidade e fixação em determinados lugares. E assim, no contrafluxo do poder da especulação imobiliária na cidade, os largos persistem com grupos e práticas, cada vez mais excluídas dos espaços públicos, num arranjo muito próximo do que Milton Santos chamou de rugosidades:

O que na paisagem, representa um tempo passado, nem sempre é visível como tempo, nem sempre é redutível aos sentidos, mas apenas ao conhecimento. Chamemos rugosidade ao que 
fica do passado como forma, espaço construído, paisagem, o que resta do processo de supressão, acumulação, superposição, com que as coisas se substituem e acumulam em todos os lugares. As rugosidades se apresentam como formas isoladas ou como arranjos. É dessa forma que elas são uma parte desse espaço-fator (SANTOS, 2009, p. 140).

0 terceiro momento, nesse avanço de tratar dos largos, e através dele encontramos as geometrias de poder, e assim conhecendo melhor os agentes que interferem na produção do espaço a partir dos territórios. 0 território foi aqui entendido como resultado e condição, ele mesmo da territorialização (HAESBAERT, 2004). É substantivado por territorialidades, considerando uma abordagem lefebvreano sobre a produção do espaço geográfico. Essa é a forma. E para um bom caminho na compreensão dos múltiplos conteúdos do tempo-espaço-território é importante considerar os diversos tempos coexistentes (novo e velho) e diversas escalas de perspectiva também existentes (próximo e distante). E para se ter uma ideia da dimensão dessa teia de relações, a seguir um apanhado de imagens e folders usados como chamada para atividades nos largos da cidade de Porto Alegre:
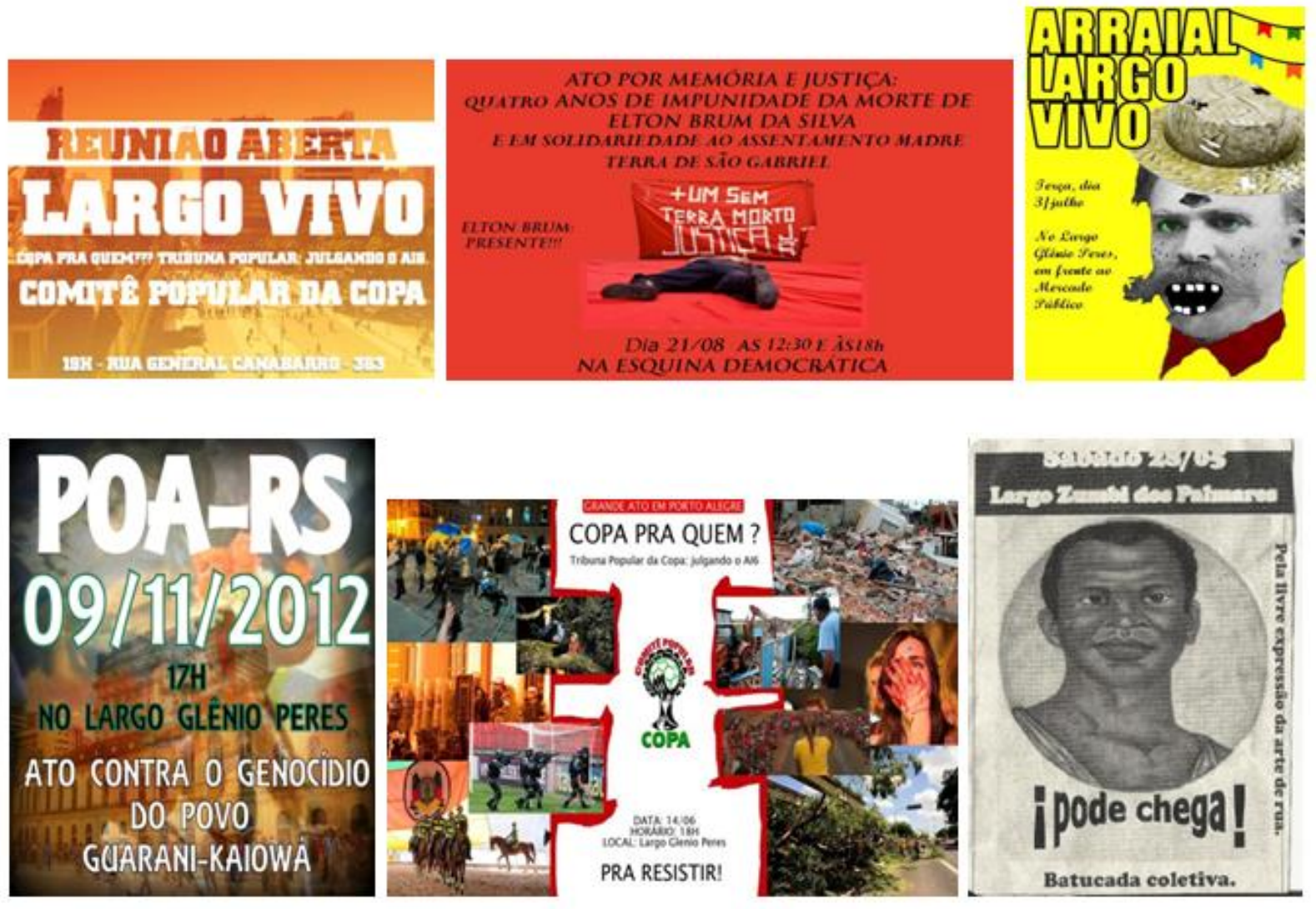


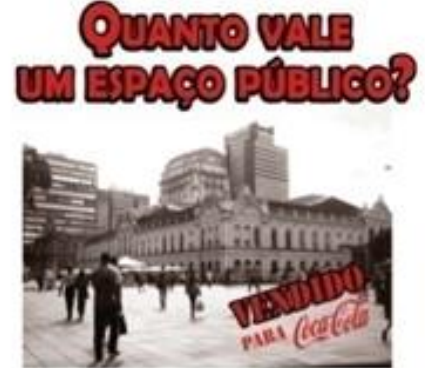

Dia 5/6

DIA MUNDIAL. DO MEIO AMBIENTE

$12 \mathrm{~h}$ em frente à prefeitura de Porto Alegre

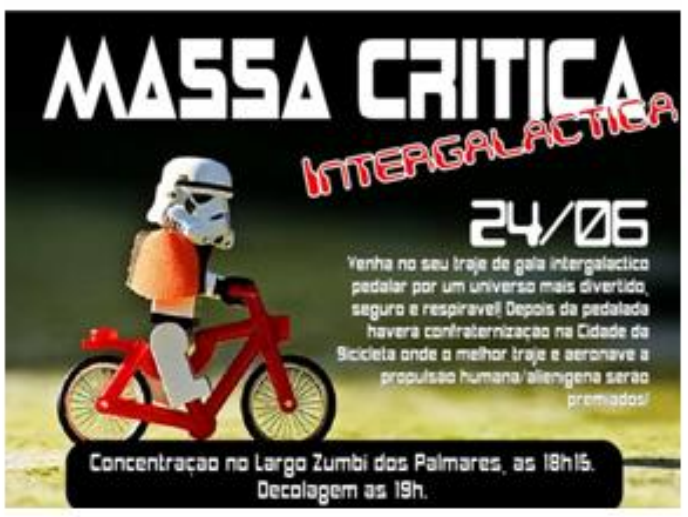

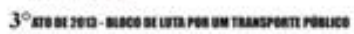

"VEM PRA LUTA, VEM CONTRA O AUMENTO"

$18 / 02-17: 30$ Largo Glènio Peres

CONTRA O AUMENTO ABUSIVO DA PASSAEE "A 2* TRAIFA MALS CARA DO PRIS"

Pen um raskspontr pésuco

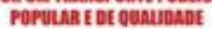
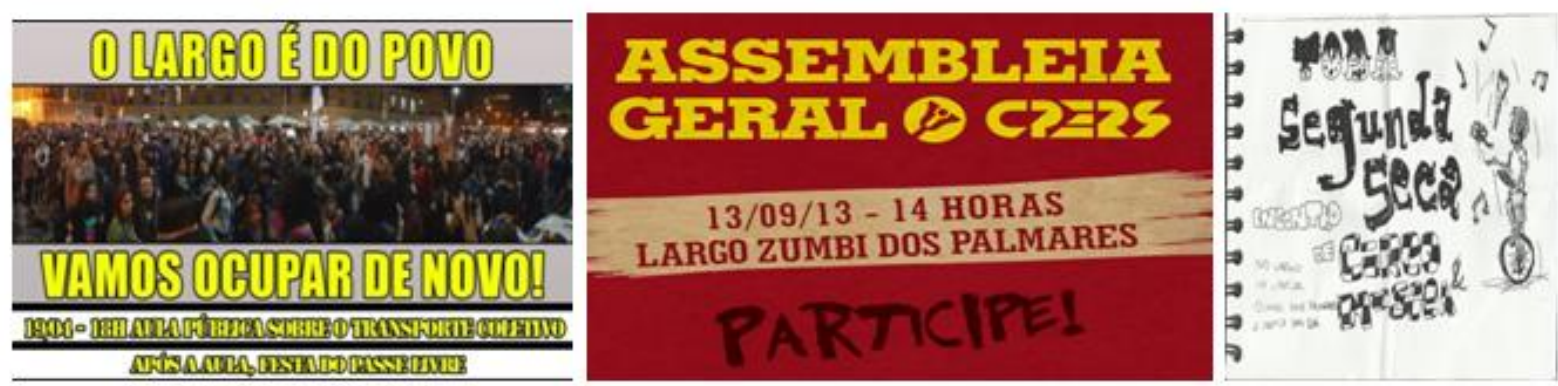

Fonte: acervo da autora, 2011, 2012 e 2013.

O quarto e último momento ancoramos no conceito de lugar e assim, nas multiplicidades das escalas vistas a partir do largo. 0 local e o global se cruzam potencializando o largo como o lugar dos usos e apropriações alternativas da cidade de Porto Alegre. Além disso, o largo não é só o lugar da relação, da conexão e das aproximações, ele é também o lugar da memória. Lá é também o lugar onde os usos e apropriações específicas desses espaços públicos encontram como morada histórica, onde perpetuaram por tanto tempo, mesmo contrariando várias imposições da cidade enquanto mercadoria.

\section{Considerações Finais}

O exercício proposto como metodologia, e feito durante o desenvolvimento da pesquisa sobre a produção do espaço dos largos em Porto Alegre, considerou como "chaves" de leitura e análise os conceitos de paisagem, espaço, território e lugar a fim de refletir sobre as potencialidades desses espaços públicos especificamente. Mais que isso, nossa intenção foi oferecer um arcabouço metodológico transdisciplinar aplicável ao objeto a que nos propusemos estudar, e também possa servir de instrumentalização para futuras pesquisas que tratem dos largos. Muito longe de espaços vazios ou decadentes na cidade, os largos oferecem um universo de multiplicidade e diversidade, e necessitam por isso de instrumentos metodológicos que atendam a essa amplitude.

Difícil encontrar um termo que resuma tal multiplicidade, porém em um exercício de síntese podemos dizer que as produções dos largos na cidade de Porto Alegre nos levaram uma grande intersecção. Um cruzamento entre conceitos, metodologias, usos e apropriações em diferentes escalas evidenciadas no mesmo lugar, porém não restrito as fronteiras de suas arquiteturas. Uma intersecção que nunca será neutra, já que propomos uma análise crítica sobre as condições de diversidade e de conflitos, fruto das contradições na produção do espaço dos largos. 


\section{Referências}

GOMES, Paulo C.C. A Condição Urbana: ensaios de geopolítica da cidade. $3^{\text {a }}$ Ed., Rio de Janeiro: Bertrand Brasil, 2010.

HAESBAERT, R. O mito da desterritorialização: do "fim dos territórios", à multiterritorialidade. Rio de Janeiro: Bertrand Brasil.

LATHAM, A.; MCCORMACK, D.; MCNAMARA, K.; et.at. Key Conceptism. Urban Geography: Londonisage, 2009.

LEFEBVRE, Henri. La produccion Del Espacio. Espanha: Editora Capitan Swing II, 2013.

MASSEY, Doreen B. Pelo Espaço: uma nova política da espacialidade. Rio de Janeiro: Bertrand Brasil, 2008.

MONTEIRO, Charles. Porto Alegre e suas escritas: histórias e memórias da cidade. Porto Alegre: EDIPURS, 2006.

MONTEIRO, Charles. Porto Alegre: urbanização e modernidade: a construção social do espaço urbano. Porto Alegre: EDIPURS, 1995.

SANTOS, Milton. A natureza do espaço: Técnica e Tempo, Razão e Emoção. São Paulo: Editora da Universidade de São Paulo, 2009. 